are attributed to 'instability' and invalidated in consequence. If she persists in this behaviour, she may even be shipped off to the nearest psychiatric hospital, while her husband, genuinely concerned by her behaviour, remains oblivious to his own part in the scenario.

Returning to the consultants, their own helpless chaotic response to the deteriorating climate may well invalidate their perspective in the eyes of the administration. Bypassed in major decision making, criticised for their narrow partisan concern with their patients' interests, and increasingly blamed for the whole situation, they are in danger of suffering the metaphoric equivalent of being 'put away'.

If this analysis is valid there is only one prescription. In the marital situation, treatment involves helping each party to become aware of their contributions to the deteriorating relationship. The financial arrangements between them often mirror the dynamics with remarkable accuracy. In the case referred to above, the husband had total control over finances, giving his wife 'housekeeping money' which she consistently mismanaged, only confirming his view of her as irresponsible. She was in ignorance of his earnings, the gravity of their financial position (which he thought would 'disturb' her) and many details of their expenditure.

When it was suggested that all accounts should be joint and that time should be put aside for joint planning of expenditure, the husband admitted to an immediate sense of panic as he saw his calm control disappearing and was faced to re-own his own unacknowledged anxiety which his wife had been carrying for him. His wife felt an immediate sense of relief and a surge of confidence in response to being treated like an adult.

The health service is a partnership. It cannot function without doctors but it also needs people with administrative and financial expertise in order to manage effectively. Partnerships do not work unless they have equal shared power responsibility and control.

The implication is clearly that unless consultants are given clinical budgetary control on a par with administrators' control of support service budgets, their influence will diminish, their patients will suffer, and the overall climate and morale in the service will continue to deteriorate.

Comments please!

Netherne/St George's Hospitals

Coulsden, Surrey

I. F. MACILWAIN

\section{The Draft Code of Practice and psychosurgery}

DeAr Sirs

Dr Peter Turner's recent letter concerning the Mental Health Act $^{1}$ mentions the extraordinary way that patients are treated by the Mental Health Act Commission when they wish to be considered for psychosurgery, and previous correspondence has stressed this ${ }^{2.3}$. In effect they are deprived of their rights and compelled to see a doctor, to whom they have not been freely referred. They must be interviewed by others, who could include a Mayor or someone from a consumers' group, whether they regard this as reasonable or not. How many ill people want to be asked questions about their illness by Mayors and consumer personnel?

Much of the legislation in Section 57 seems designed for an east European country where the party machine knows best. Indeed, Lord Colville seems to confirm this in the quotation given in Dr Turner's letter where Lord Colville confers medical infallibility on the Secretary of State.

It may be that others would like to know our main criticisms of the Draft Code of Practice. We are specially concerned about the following:

5.8.3 When a patient is referred to the Mental Health Act Commission under Section 57 the appointed Doctor will expect the RMO to show that-....

other circumstances are favourable, such as premorbid personality, support by family and/or others: ....

there has been full and up-to-date multidisciplinary assessment, including psychological, nursing, social, domestic, physical and vocational.

We are strongly of the opinion that psychosurgery should not depend upon whether 'other circumstances are favourable, such as...' etc. These aspects tended to be stressed with prefrontal leucotomy but that was used over 30 years ago. The indirect results of most major operations, including those for carcinoma for example, are enhanced to some extent by a favourable premorbid personality, support by the family and so on. But lack of these benefits is in no way a contraindication to surgical treatment. They are important but essentially peripheral factors. Psychosurgery is needed because of severe and intractable affective disorders and, while the overall outcome may be rather less good because of an absence of favourable home circumstances for example, this does not in any way mean that the operation should not be carried out. Surgery is needed to relieve the distress of the patient.

In our view it is not essential to have a full and up-to-date multidisciplinary assessment before psychosurgery is considered. This point is similar to that above. Multidisciplinary information is useful and desirable but not essential. The absence of this information must not unduly delay much-needed treatment.

Let us be quite clear that assessing a patient for a psychosurgical operation involves a highly specialised neurosurgical and psychiatric decision, with the neurosurgeon having a veto. This decision, to operate or not, is entirely medical and does not involve any other profession directly.

However, the most important matter of all does not appear in the Draft Code. I refer to the imperative need for an appeal procedure, especially with regard to assessments for psychosurgery. It should be quite unacceptable in a democratic society for a very ill patient to be forced to submit to the opinions of medical commissioners whose experience of psychosurgery has so far seemed to be limited at 
best and often absent. We now know that the Commission currently has experience of 57 patients assessed for psychosurgery ${ }^{4}$ and even this experience is divided between several of the Commission's doctors. The patients are seen only once and there is no clinical experience of trying alternative forms of therapy and of post-operative rehabilitation and follow-up. How can it be reasonable that these decisions over-ride the opinions of the multidisciplinary staff of this Unit, as pointed out by Dr Turner in his letter? In more general terms, how can psychiatry ever advance if the clinical policies of an innovative unit are dominated by two retired consultants and a psychogeriatrician?

We agree with the Commission that patients should have available all reasonable information about their illness and its management, and their rights should at all times be protected. To this end, when our recommendation to operate has been over-ruled by commissioners, we intend to encourage the patients and their families, with the permission of the referring doctors, to obtain detailed reasons from the Commission about the decision and about the doctor involved in the decision, and if appropriate, to ask for an independent opinion acceptable to the patient and his medical advisers, as is the traditional medical right of patients.

We would like to make clear that the advent of the Commission has not changed our clinical policies. It is not our experience that our psychosurgical practice has been curtailed to any great extent by the Commission although there have been difficulties with individual patients. We hope that consultants will not feel that the presence of the Commission inhibits them from referring patients for our assessment, if they wish to do this. Indeed, it seems to us of paramount important that the very distressed patients who we may be able to help will not be denied adequate treatment because of the preseumed antagonism of the Commission. After all, our experience has been that medical commissioners have agreed to operations in the case of 34 of our patients out of 39 referred to them up to the end of 1985.

The Geoffrey Knight Psychosurgical Unit

Paul Bridges

Brook General Hospital

London SE18

REFERENCES

'Turner, P. (1986) Mental Act 1983, Bulletin of the Royal College of Psychiatrists, 10, 53.

${ }^{2}$ Berdoces, P. K. (1984) Psychosurgery and the Mental Health Act Commission. Bulletin of the Royal College of Psychiatrists, 8, 146-148.

${ }^{3}$ Thompson, C. (1985) An open letter to Lord Colville. Bulletin of the Royal College of Psychiatrists, 9, 100.

4The First Biennial Report of The Mental Health Act Commission 1983-85. London: HMSO, October 1985.

\section{Senior registrars' posts in old age psychiatry} DeAR Strs

Blessed has reviewed the declared need for more consult- ants to develop and run services for the elderly and has provided evidence that the number of suitable training posts at senior registrar level is increasing ${ }^{1}$. Among the difficulties facing manpower planners at present is ignorance of the subsequent careers of trainees who pass through these posts. We have reviewed the careers of doctors who have taken advantage of the training posts identified in an earlier survey $^{2}$ to determine the yield from these posts during the years 1980-1986, by gathering information from the named trainers (See Table I). In particular we have been interested to clarify differences in outcome when trainees applied directly to these posts compared with rotation as part of a general psychiatry training scheme of other modes of appointment:

All the posts offering direct appointment to a training in old age psychiatry offered full-time training in the sense that Blessed has defined. All but one of the 16 senior registrars who have progressed to consultant appointments are dedicated to old age.

Not all of the 'rotation posts' offer full-time training and there is a trend for those offering more training to achieve a greater yield of career psychogeriatricians (See Table II). Nevertheless the yield is less than 1 in 3, the majority of trainees becoming general psychiatrists and only a minority of them having formal sessional commitments to services for the elderly.

Research posts, part-time posts (PM(79)3) and a special secondment were much more likely to lead to careers in old age psychiatry. In the main those trainees/researchers had made their intentions clear in organising their own training.

If the yield from newly established posts is similar to that for those that have been available up to now, the creation of more posts which are filled by rotation from within general psychiatry training schemes will be disappointingly low and a very large number of such posts will be needed to fill predicted requirements at consultant level. This may be an ideal way to respond to the problem and would have the benefit that many general psychiatrists would have a greater working knowledge of the disorders of old age and the services available to manage them. The alternative of dedicating more posts to old age psychiatry from appointment is likely to produce more career-psychogeriatricians from each post and trainees should have the opportunity to achieve a more comprehensive specialist training than is possible in a one year rotated attachment.

It seems probable that the best course is a middle-road, with some posts offered as part of a general psychiatry rotation reaching out to trainces who are interested but undecided, and others responding to the wishes of those who are committed to the work but who would prefer a wider and deeper exposure to the subspeciality by direct appointment.

DAVID JOLLEY RUTH HORTON

Psychogeriatric Unit

Withington Hospital, Manchester 